THERMAI DEGRADATION STUDIES OF SEVERAL PYRRONE FIIMS*

$$
\begin{aligned}
& \text { By Robert A. Jewel1 } \\
& \text { NASA Langley Research Center } \\
& \text { Spacecraft Matexials Section } \\
& \text { Langley Station, Hampton, Va. }
\end{aligned}
$$

SXNOPSIS

The thermal degradation of several polyimidazopyrrolone (Pyrrone) films was studied in air and in vacuum over the range of $100^{\circ} \mathrm{C}$ to $1,000^{\circ} \mathrm{C}$ by thermogravimetric analysis (TGA), using both isothermal heating and programed heating rates of $2^{\circ}, 3^{\circ}, 5^{\circ}$, and $7.5^{\circ} \mathrm{c} /$ minute. At pressures of $10^{-6}$ torr or less, maximum weight losses average 30 percent at $800^{\circ} \mathrm{C}$. Rates of volatilization and activation energies were derived to provide comparison between these ladder-type polymers. Mass spectrometric analysis of the pyrolysis gases evolved under vacuum conditions showed that $\mathrm{CO}, \mathrm{CO}_{2}$, and $\mathrm{H}_{2} \mathrm{O}$ were the primary volatile products and that they were formed throughout the period of weight loss. Approximate correlation between changes in weight and changes in the total pressure for the vacuum tests indicates that mass spectrometric results could provide quantitative as well as qualitative data. The importance of sample history prior to heating and of sample geometry in developing meaningful and reproducible TGA results is aptly demonstrated. The ability of these materials to absorb readily 5 to 7 percent, by weight, of water under ambient conditions and the effect of this property upon weight loss measurements are shown.

*Presented at the 18th Southeastern Regional Meeting of the American Chemical Society, October 27-29, 1966, Louisville, Kentucky.
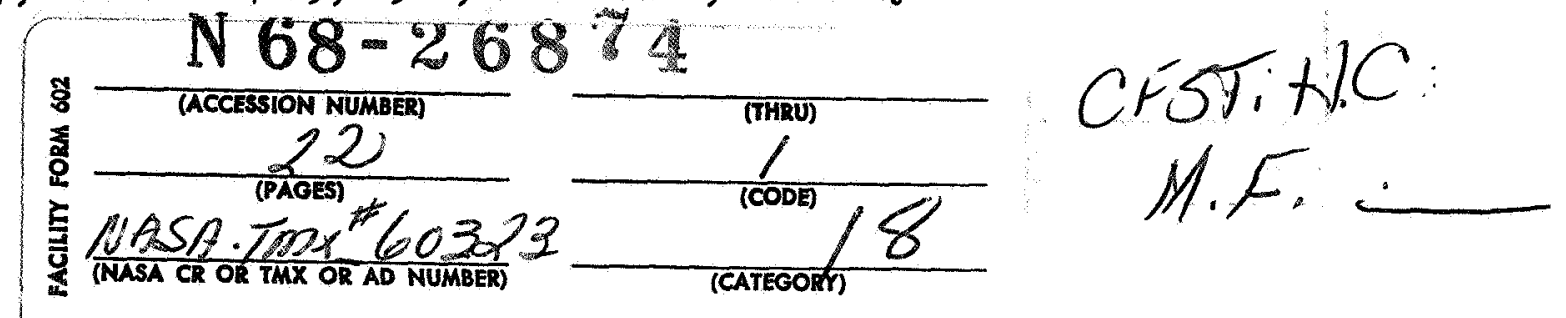


\section{THERMAL DEGRADATION STUDIES OF SEVERAL PYRRONE FILMS}

By Robert A. JewelI

NASA Langley Research Center

Spacecraft Materials Section

Langley Station, Hampton, Va.

\section{INTRODUCTION}

The thermophysical behavior of several polyimidazopyrrolone (Pyrrone) polymers (ref. I), was investigated (I) to relate chemical structure to thermal stability, and (2) to aid the direction of exploratory synthesis of this class of aromatic/heterocyclic meterials. Combining some of the desirable chemical and physical properties of the polyimides and the polybenzimidazoles, the Pyrrones hold considerable potential for speclalized aerospace and terrestrial uses.

- Thermogravimetric analysis (TGA) in air and in vacuum of four films from these "step-ladder" materials suggests some preliminary indication of ways to improve their thermal stabilities. Both isothermal and dynamic heating were used to derive rates of volatilization and activation energies. The comparison of TG curves, as well as the results from other measurements such as differential thermal analysis (DTA) and residual gas analysis, were used to detail the modes of thermal degradation.

\section{EXPERIMENTAL}

\section{Description of Materials}

The polyimidazopyrrolones were prepared using two aromatic dianhydrides: pyromellitic dianhydride (PMDA) and 3, 3', 4, 4'benzophenone tetracarboxylic dianhydride (BTDA). Two tetramines were polymerized with each of

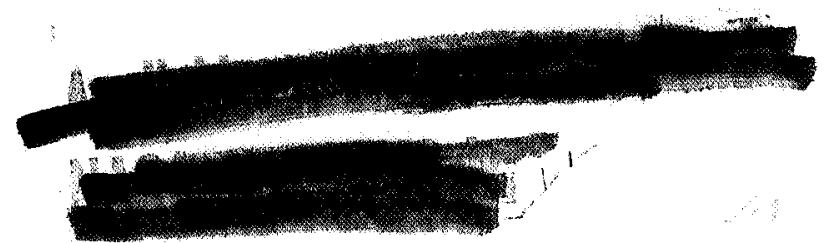


the two dianhydrides: 3, 3'-diaminobenzidine (DAB), and 3, 3', 4, 4'tetraaminodiphenyl ether (TADPO). Their proposed stmuctural repeating units are shown in table 1. Synthesis and characterization of these polymers have been reported elsewhere (ref. 2).

Films were formed by casting polymer solutions onto glass plates and by drying them to soluble films in a forced airflow oven at $125^{\circ} \mathrm{C}$ for 1 hour. After the films were stripped from the plates, they were postcured at $350^{\circ} \mathrm{C}$ in air for 2 hours. Test specimens $0.635 \mathrm{~cm}$ in diameter, with a nominal thickness of $0.0025 \mathrm{~cm}$ and initial. weights of $2.05 \mathrm{mg} \pm 0.03 \mathrm{mg}$ were cut from the films.

\section{Description of Equipment and Test Procedures}

The TG equipment used for vacuum exposures was an essentially all. metal-glass system, with ion pumps maintaining sample environmental pressure at $10^{-6}$ torr or less at all times. The main components were (I) a Cahn RG null-type electrobalance, (2) quartz suspension fibers, (3) 3/8-inch-0.a. by 1/8-inch-high platinum sample pan, (4) chromel-alumel thermocouples within the vacuum chamber, and (5) a 2-inch-diameter by 12-inch-long furnace with adjustable tapping to guarantee a large evenly heated reaction zone. In addition to the necessary ion gages, power programmer, and recorders, an R-C circuit provided-an instantaneous first derivative of the weight-Ioss curve, and a Vanderslice type mass spectrometer permitted partial pressure measurements. Separate electrobalance equipment similarly arranged was used for tests made in air. DTA data were obtained with a DuPont 900 DPA unit.

In each test the initial weight was determined after preconditioning the sample at $100^{\circ} \mathrm{C}$ for 30 minutes. Isothermal temperatures in the $400^{\circ}$ to 
$460^{\circ} \mathrm{C}$ region required an average of 8 minutes to reach thermal equilibrium and were maintained within $\pm 0.5^{\circ} \mathrm{C}$. Nonisothermal heating rates of $2,3,5$, and $7.5^{\circ} \mathrm{C} / \mathrm{min}$ were held within $\pm 1.5^{\circ} \mathrm{C}$ during the entire period of heating. The large surface-to-volume ratio of the small specimens and the Iarge uniformiy heated reaction zone were felt to justify the use of the sample pan temperature as the temperature of the material (ref. 3). Dummy runs, where a thermocouple was electron-beam welded to a pan, provided the means to correlate surrounding temperature to pan temperature.

Activation energies $E$ were derived by employing the method of

H. Anderson (ref. 4). Data from multiple isothermal tests can provide for the complete solution of the equation:

$$
\log (d w / d t)=\log A+n \log \left(w_{i}-w\right)-E / 2 \cdot 3 R T
$$

where

w weight lost during time $t$ at temperature $\mathrm{T}\left({ }^{\circ} \mathrm{K}\right)$

A Arrhenius preexponential factor

$n$ order of decomposition

$w_{i} \quad$ initial sample weight

R gas constant

E activation energy

For data from tests using constant ates of heating the left side of equation (I) becomes

$$
\operatorname{Iog}[(\alpha w / \partial T)(\alpha T / \partial t)]
$$

By varying either temperature $T$ or rate of heating $d T / d t$, all unknowns in the equation can be determined. The major limitation relates to the complex manner of degradation of Pyrrone films, so that the derived value $E$, is really an effective value of all the individual $\mathrm{E}^{\prime} \mathrm{s}$ involved. 


\section{DISCUSSION \\ Results in Air}

Isothermal TG results in air are presented in figures 1,2 , and 3 . As seen in figure 1, weight-loss curves for BTDA-DAB, the most thermally stable of the four films tested, show that initially there is a rather large fraction volatilized. Since the films had been postcured at $350^{\circ} \mathrm{C}$, this loss suggests thermal instability in air above $400^{\circ} \mathrm{C}$, rather than further polycondensation.

In figure 2, the plateaus in the curves show that at least 40 percent of the sample was lost at a nearly constant maximum rate, which denotes optimization of test parameters.

Figure 3 presents the data from the plateau regions (48 to 53 percent of volatilization) of figure 2 as Arrhenius plots. The three temperatures involved are $440^{\circ} \mathrm{C}, 450^{\circ} \mathrm{C}$, and $460^{\circ} \mathrm{C}$. By using the slopes of the lines of figure 3, activation energy $E$ values were calculated from equation (I). Numerical values of $E$ ranged from 28 to $34 \mathrm{Kcal} / \mathrm{mole}$ and are listed indivicually for the four polymers in figure 3 .

Results from nonisothermal heating tests are shown as thermograms in figures 4 and 5. Figure 4 shows the effect of varying the heating rate on the thermograms of the polymer, PIDA-DAB. As heating rate increases, the inaicated temperature stability increases which is consistent with the fact that volatilization proceeds at a finite rate.

As was done for the isothermal data, Arrhenius plot treatment was given the data depicted in figure 4 in the vicinity of 50 percent volatilization. 
The average value of $\mathrm{E}$ approximated $31 \mathrm{Kcal} / \mathrm{mole}$, which agrees with the value obtained from isothermal data.

In figure 5 thermograms generated at a heating rate of $5^{\circ} \mathrm{c} / \mathrm{min}$ reveal that the two polymers made from BTDA exhibit identical behavior from $100^{\circ} \mathrm{C}$ to $480^{\circ} \mathrm{C}$, where a knee develops. The two curves separate at approximately $500^{\circ} \mathrm{C}$, with the BTDA-DAB polymer exhibiting slightly greater temperature stability.

Examination of the curves in figure 5 for the two polymers made from PMDA reveals that the initial weight change experienced by the PMDA-TADPO polymer represents loss through further polycondensation, suggesting an incompletely curved sample. This conclusion was confirmed by an experiment in Which another PMDA-TADPO sample was postcured at $350^{\circ} \mathrm{C}$ for 2 hours before its thermogram was determined. The more stringently postcured sample produced a thermogram which coincided with the curve for PMDA-DAB until commencement of rapid degradation at $460^{\circ} \mathrm{C}$.

In order to eliminate the effect of adsorbed moisture, each film was preconditioned at $100^{\circ} \mathrm{C}$ for 30 minutes before its thermogram was determined. The importance of this step is shown in figure 6 . The data of figure 6 were obtained by alternately heating a PMDA-DAB film to $100^{\circ} \mathrm{C}$ and then cooling it to $25^{\circ} \mathrm{C}$, with a total period of 1 hour. As shown in table 2 , the ratio of the percent of water lost on heating to $100^{\circ} \mathrm{C}$ to the theoretical percent of water of conversion is a constant with a value of 0.342 .

DTA thermograms were determined in air on a BTDA-DAB polymer to ascertain whether thermal effects such as phase changes were occurring which would not appear in TGA thermograms. As shown in figure 7, the DTA results did not 
reveal any such changes, but rather substantiated the TG data. In figure 8 the maximum exotherm generated during the $5^{\circ} \mathrm{c} / \mathrm{min}$ man equated to a differential sample temperature increase of $1.2^{\circ} \mathrm{C}$. Since surrounding temperatures rather than sample temperatures were monitored, the TG thermograms were corrected accordingly.

\section{Results in Vacuum}

Figure 8 shows that, of the four Pyrrones which were heated in vacuum at $5^{\circ} \mathrm{c} / \mathrm{min}$, the $\mathrm{BTDA}-\mathrm{DAB}$ film had the greatest thermal stability. In air, the two BTDA-derived polymers were the most stable, while under vacuum the two most stable polymers were made from the DAB amine. The early weight loss experienced by the PMDA-TADPO again reflects the use of a sample cured below $350^{\circ} \mathrm{C}$. Incorporating data from a cured PMDA-TADPO test, all runs begin to level out at $800^{\circ} \mathrm{C}$, and at this point, weight losses range from 28 percent to 38 percent of initial weight. At a 15-percent weight change, the activation energies vary between 47 and $50 \mathrm{Kcal} / \mathrm{mole}$.

Since several weight loss steps or semisteps occur in each thermogram, an attempt was made to relate these changes to the mode of structural decomposition through the simultaneous use of TGA and qualitative residual gas analysis (ref. 5). Figure 9 combines the weight loss curve and the prominent mass peaks observed upon heating BTDA-DAB in vacuum at $2^{\circ} \mathrm{c} / \mathrm{min}$. The slow rate of weight loss from $100^{\circ} \mathrm{C}$ to $380^{\circ} \mathrm{C}$ was accounted for by the evolution of water only ( $\mathrm{m} / \mathrm{e}$ values of 17 and 18 predominate). Both balance and spectrometer indicated a plateau from $380^{\circ} \mathrm{C}$ to $420^{\circ} \mathrm{C}$. At $420^{\circ} \mathrm{C}$ a knee in the thermogram commences, leading into a steep rate of change at $520^{\circ} \mathrm{C}$, which reaches a maximum rate at $550^{\circ} \mathrm{C}$, and sharply declines at $620^{\circ} \mathrm{C}$. Concurrently, carbon monoxide $(\mathrm{m} / \mathrm{e}=28)$ and carbon dioxide $(\mathrm{m} / \mathrm{e}=44)$ begin " 
to evolve in great quantities at $420^{\circ} \mathrm{C}$, peaking at $550^{\circ} \mathrm{C}$ and disappearing at $620^{\circ} \mathrm{C}$. At about $500^{\circ} \mathrm{C}$, the mass 40 peak, perhaps the NCN grouping, emerges. With increasing temperature, this NCN species increases together with masses 26 and 27 ( $\mathrm{CN}$ and $\mathrm{HCN}$ ). Beyond $650^{\circ} \mathrm{C}$, mass 27 predominates. A trace of ammonia (mass I7) is evident during the main period of decomposition. These results demonstrate: (1) an early period of dehydration and (2) a subsequent simple thermal breakdown of the bonds separating the benzene rings. Theoretically, $C O$ and NCN groups in BTDA-DAB account for 28 percent of the repeating unit weight, which is the same percentage of weight loss observed experimentally upon reaching the plateau at $800^{\circ} \mathrm{C}$.

\section{CONCIUSIONS}

Some conclusions arawn from thermophysical measurements of severai polyimidazopyrrolone films are:

1. Pyrrone films show a good degree of thermal stability, particularly under vacuum conditions.

2. The films are hygroscopic.

3. Of four structural compositions studied, the BTDA-DAB polymer is the ' most thermally stable.

4. A combination of thermogravimetric and mass spectrographic data can be used to outline the route of thermal degradation and partially substantiate the proposed polymeric structure. 


\section{ACKNVOWLEDGEMENT}

The author expresses appreciation to Dr. V. L. Bell who provided the Pyrrone films used in this study, and thanks Drs. G. F. Pezdirtz and V. I. Bell for their suggestions. The assistance of P. R. Young and J. R. Tyeryar, who made the thermal physical measurements is acknowledged. 
REFEREMTCES

1. Bell, V. I.; Pezdirtz, G. F.: Pyrrone - A New Class of Aromatic StepLadder and Ladder Polymers. Presented at the Eighth National Symposium on SAMPE, San Francisco, California, May 23-26, 1965.

2. (a) Bell, V. I.; and Pezdirtz, G. F.: J. Polymer Sci., B3, 977 (1965).

(b) Dawans, F.; anà Marvel, C. S.: J. Polymer Sci., A3, 3549 (1965).

(c) Pezdirtz, G. F.; and" BelI, V. I.: NASA TN D-3148 (1965).

(d) Van Deusen, R. I.: USAF Tech. Rept. AFM2-IR-65-295 (1965).

(e) Colson, J. G.; Michel, R. H.; and Paufler, R. M.: J. Polymer Sci., $4 \mathrm{~A}-1,59(1966)$.

(f) Van Deusen, R. I.; Goins, O. K.; and Sicree, A. J.: ACS Polymer Preprints, New York Meet, Vol. 7, 528 (1966).

3. McAdie, H. A.: Instrument Society of America, July 1965.

4. Anderson, H. C.: J. Polymer Sci., C6, 175 (1963).

5. Friedman, H. I.: USAF Tech Rept. ML-TDR-64-274 (1964). 


\section{LIST OF FIGURES}

Figure 1.- Isothermal TG results in air for BTDA-DAB film.

Figure 2.- Volatilization rates of BTDA-DAB films heated isothermally in air.

Figure 3.- Arrhenius plots of maximum volatilization rates of four Pyrrone films heated isothermally in air.

Figure 4.- TG thermograms of PMDA-DAB film.

Figure 5.- TG thermograms for four Pyrrone films heated in air at $5^{\circ} \mathrm{c} / \mathrm{minute}$.

Figure 6.- Ability of PMDA-DAB film to absorb moisture.

Figure 7.- DIA thermograms in air for BTDA-DAB film.

Figure 8.- TG thermograms of four Pyrrone films heated in vacuum at $5^{\circ} \mathrm{c} / \mathrm{minute.}$

Figure 9.- Residual gas analysis, of volatiles from BTDA-DAB films heated in vacuum at $2^{\circ} \mathrm{C} /$ minute. 


\section{TABLE 1.- POLYIMIDAZOPYRROLONE REPEAT UNITS}
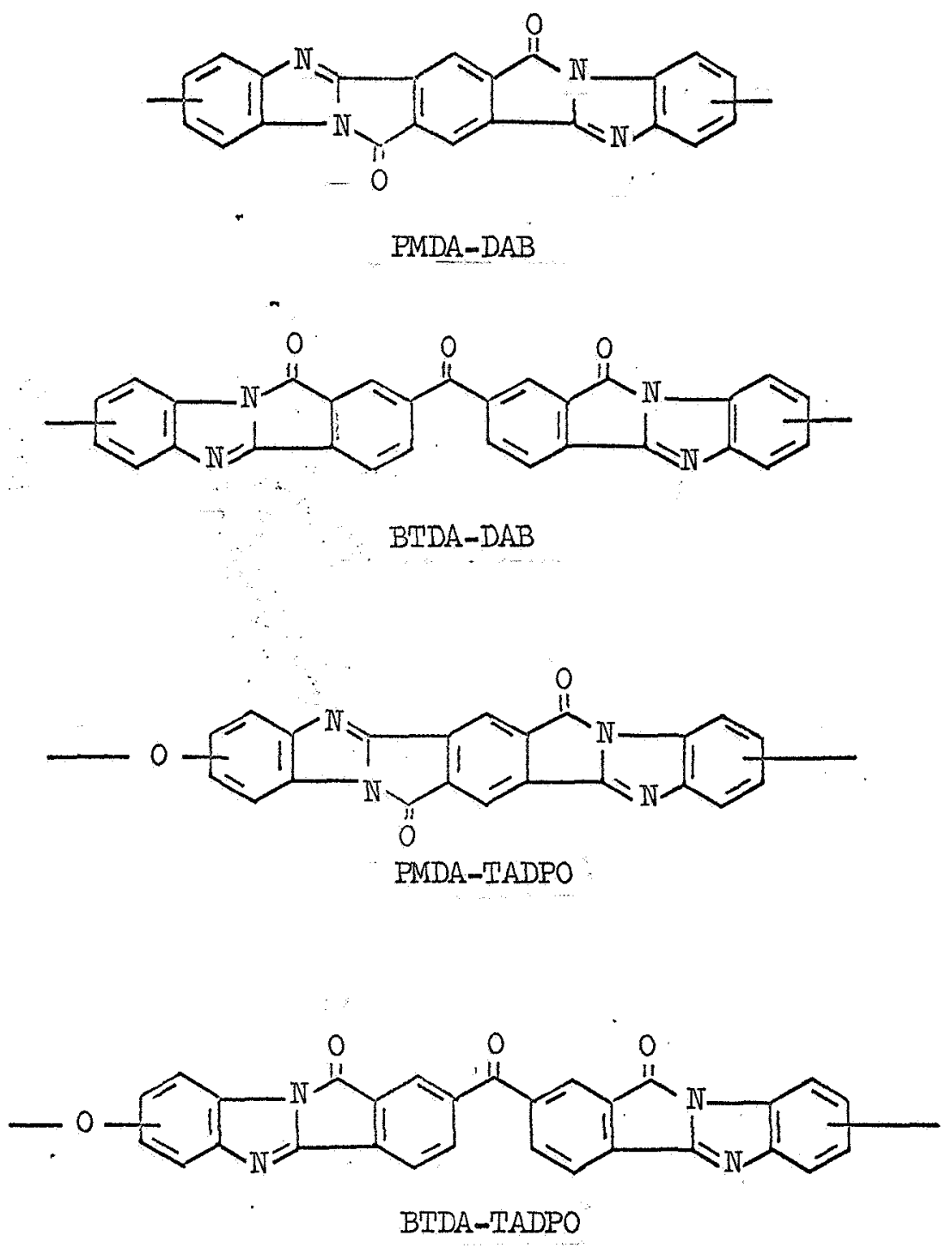
TABLE 2.- A COMPARISON OF MOISTURE CONTENT OF PYRRONE FILMS

\begin{tabular}{|l|c|c|c|c|}
\hline \multirow{2}{*}{ Material } & \multicolumn{3}{|c|}{ Theoretical } & Experimental \\
\cline { 2 - 5 } & $\begin{array}{c}\text { Molecular weight } \\
\text { of repeat unit } \\
\text { A }\end{array}$ & $\begin{array}{c}\text { Percent of water } \\
\text { of condensation } \\
\text { B }\end{array}$ & $\begin{array}{c}\text { Percent weight change } \\
\text { on heating to 100 } \\
\text { C C }\end{array}$ & $\begin{array}{c}\text { Ratio of } \\
\text { column C } \\
\text { to } \\
\text { column B }\end{array}$ \\
\hline PMDA-DAB & 360 & 20.0 & 6.90 & 0.345 \\
PMDA-TADPO & 376 & 19.2 & 6.55 & .337 \\
BTDA-DAB & 452 & 15.9 & 5.41 & .340 \\
BTDA-TADPO & 468 & 15.4 & 5.32 & .345 \\
\hline
\end{tabular}




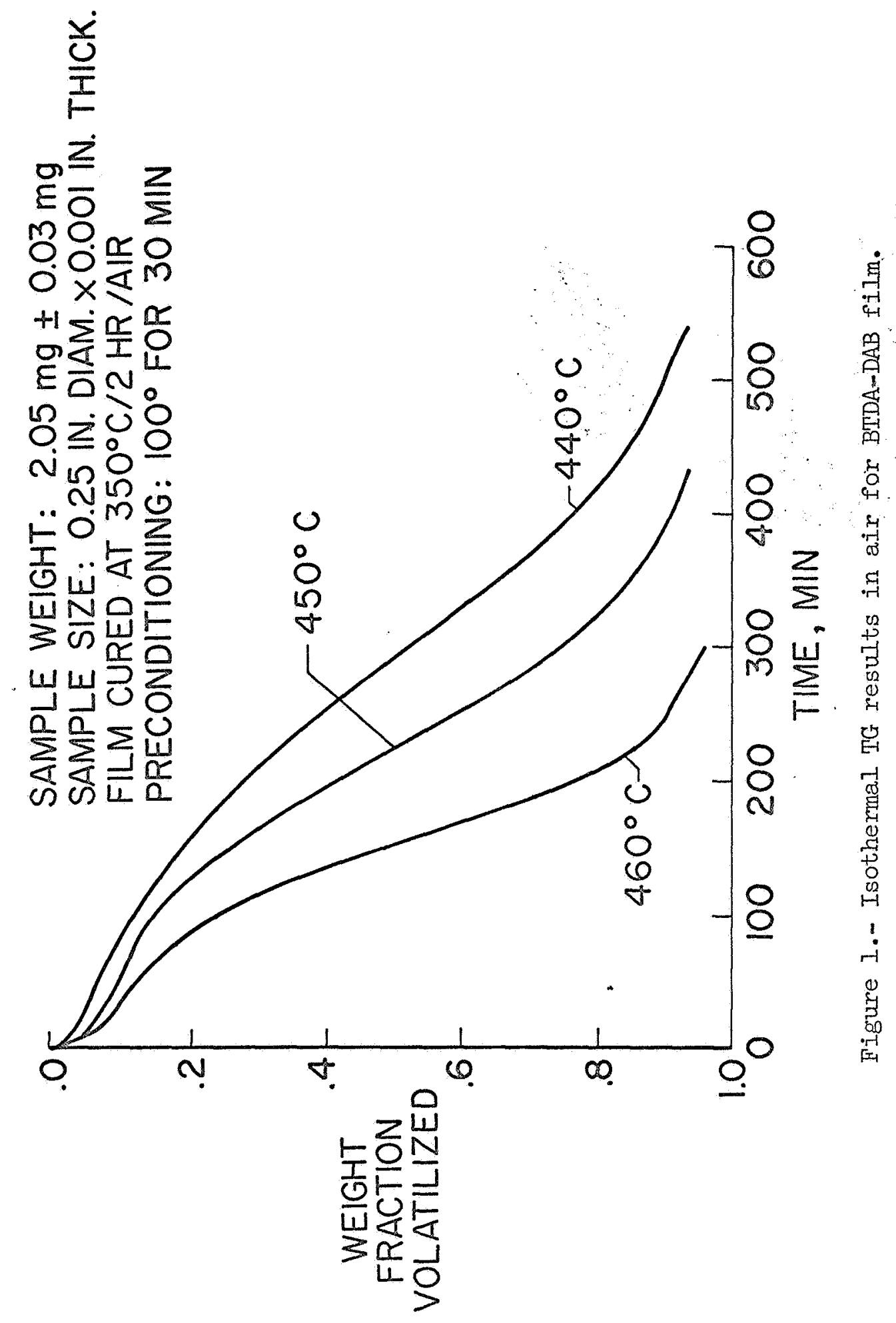




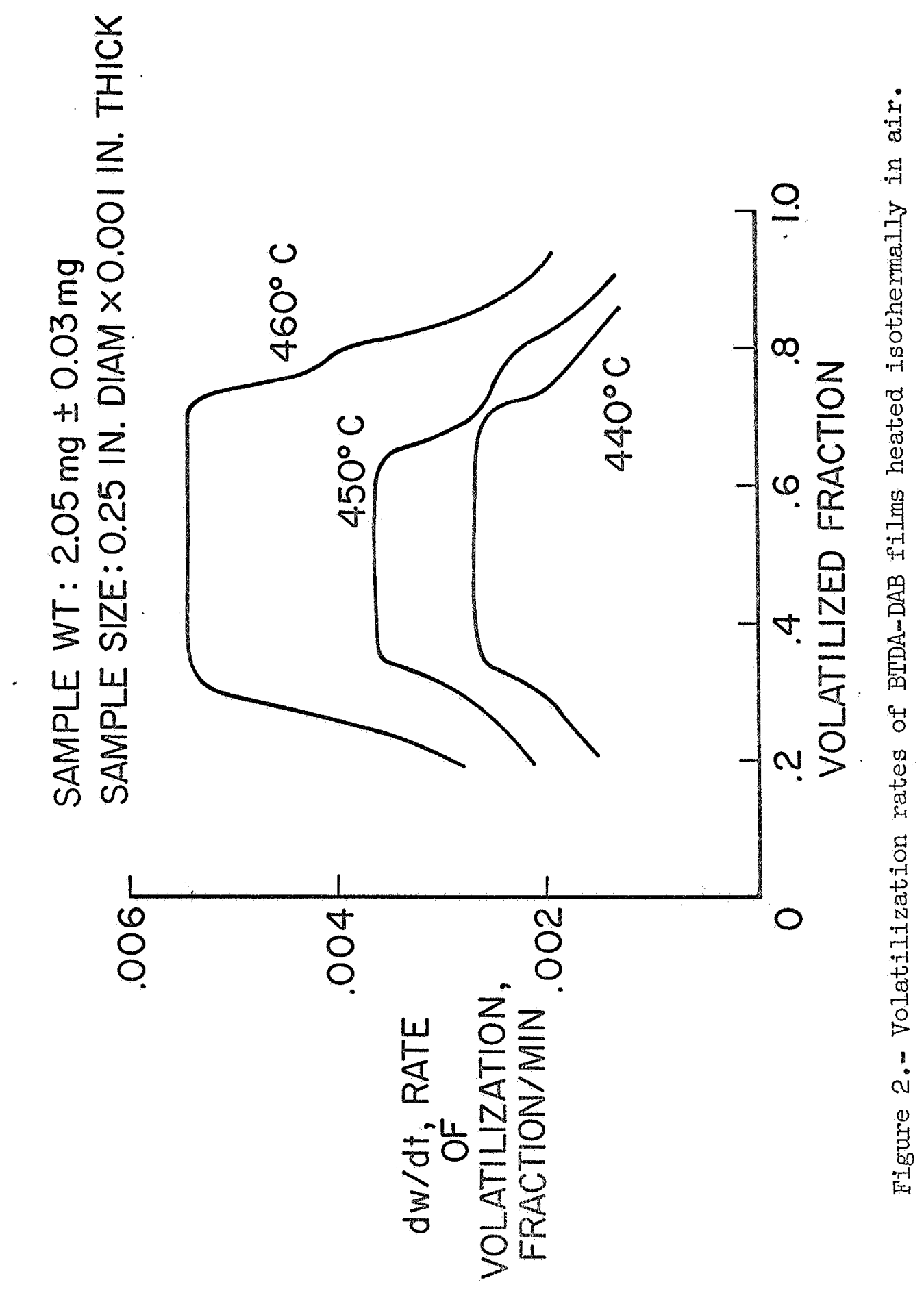




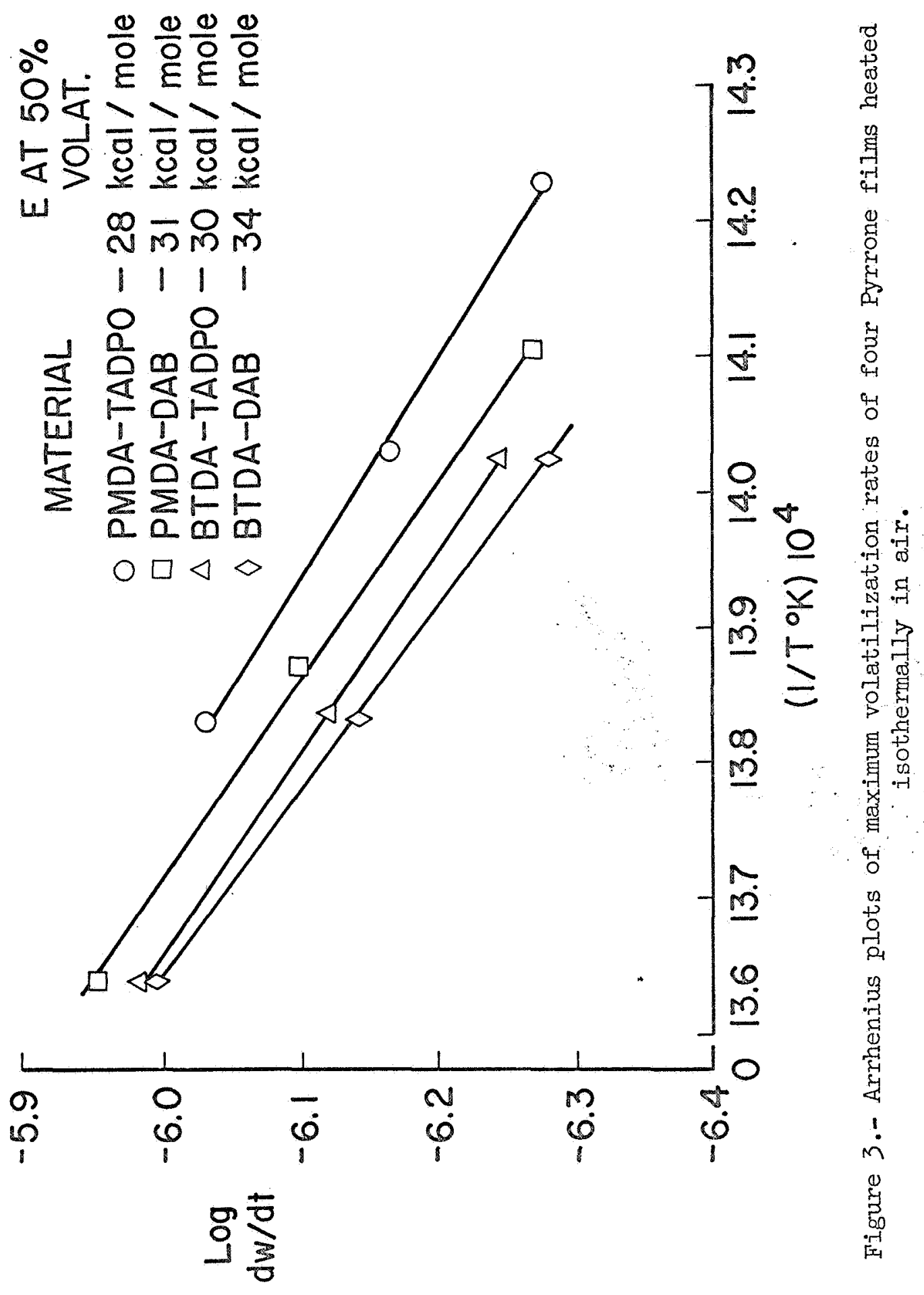




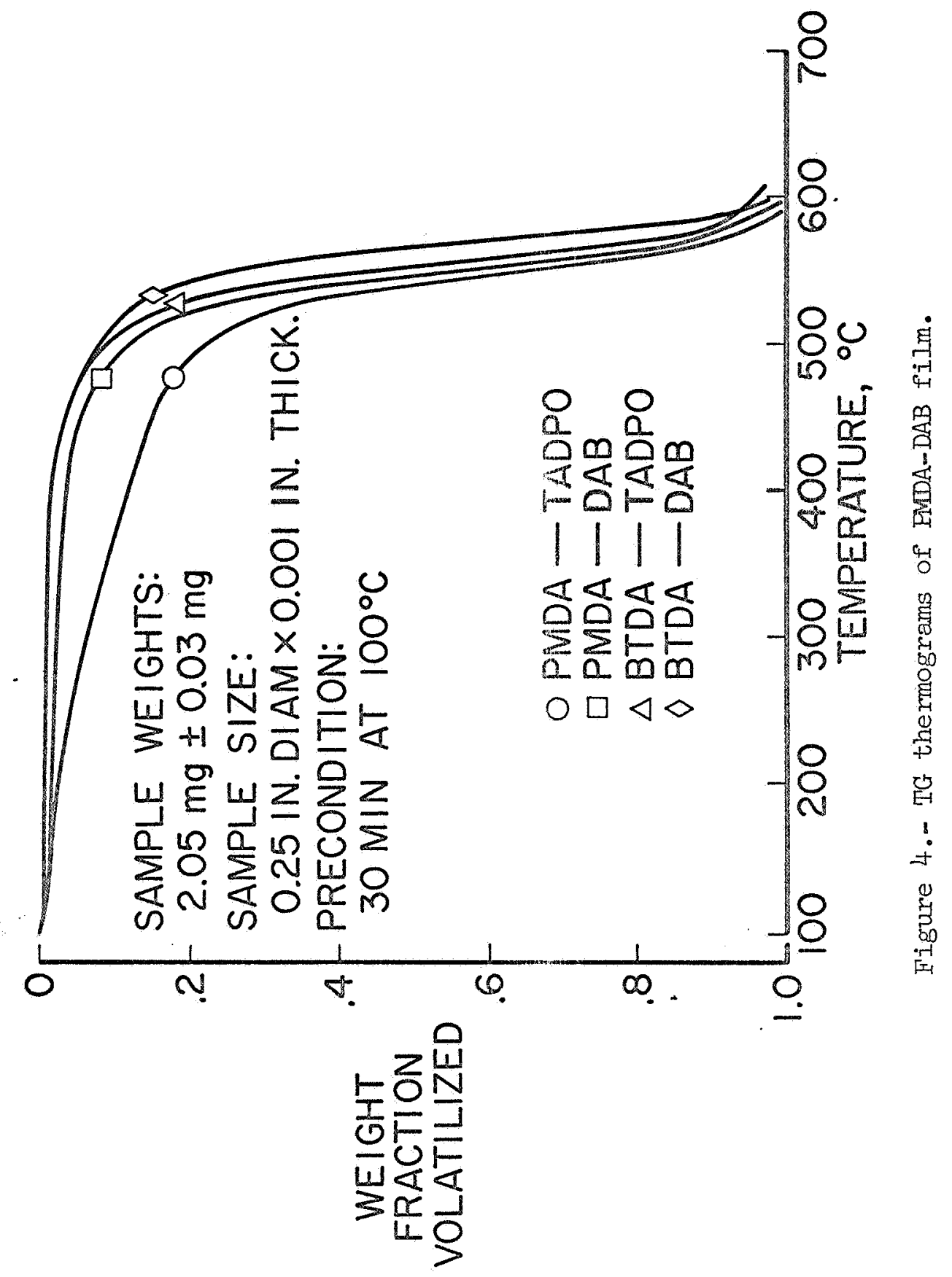




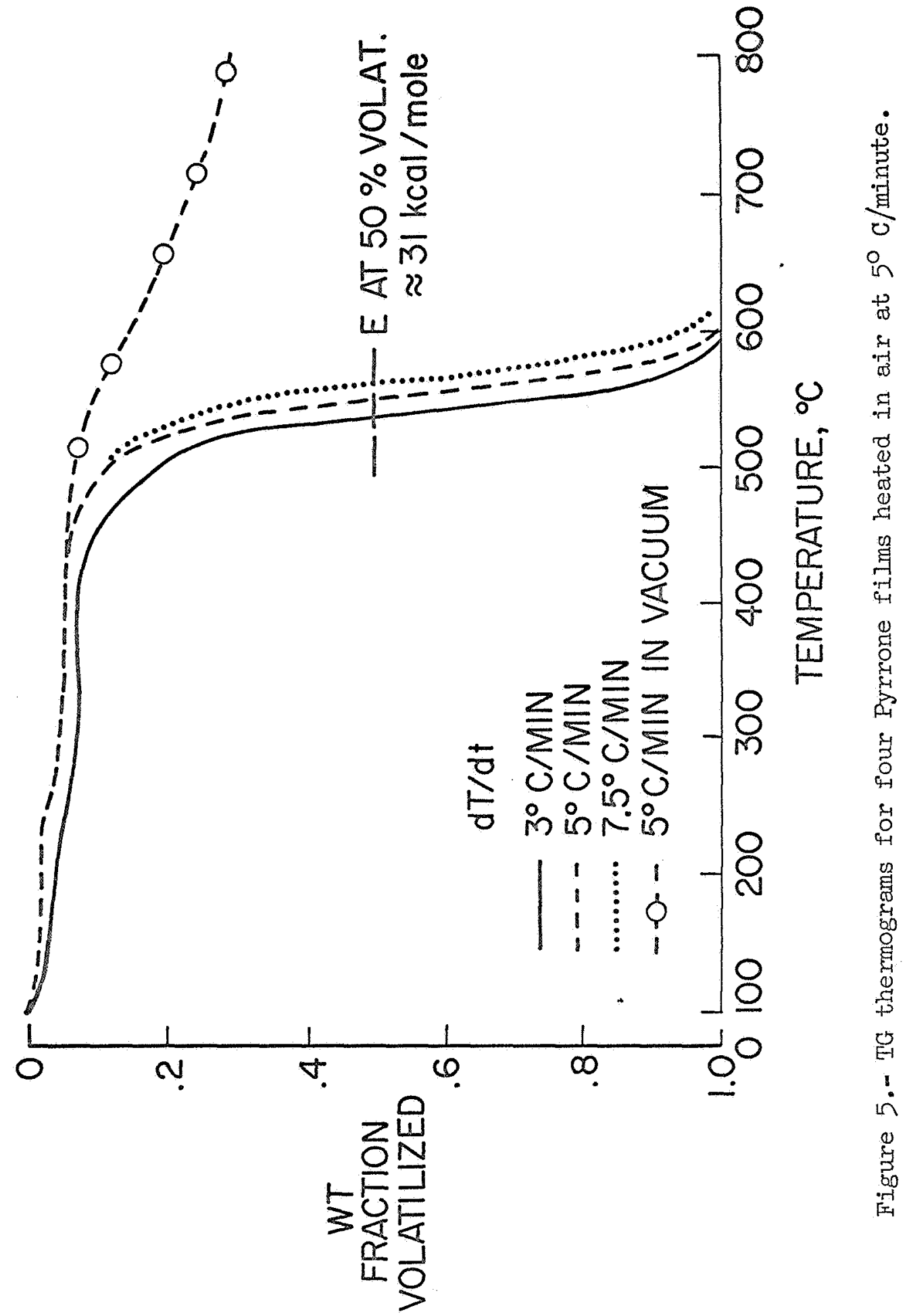




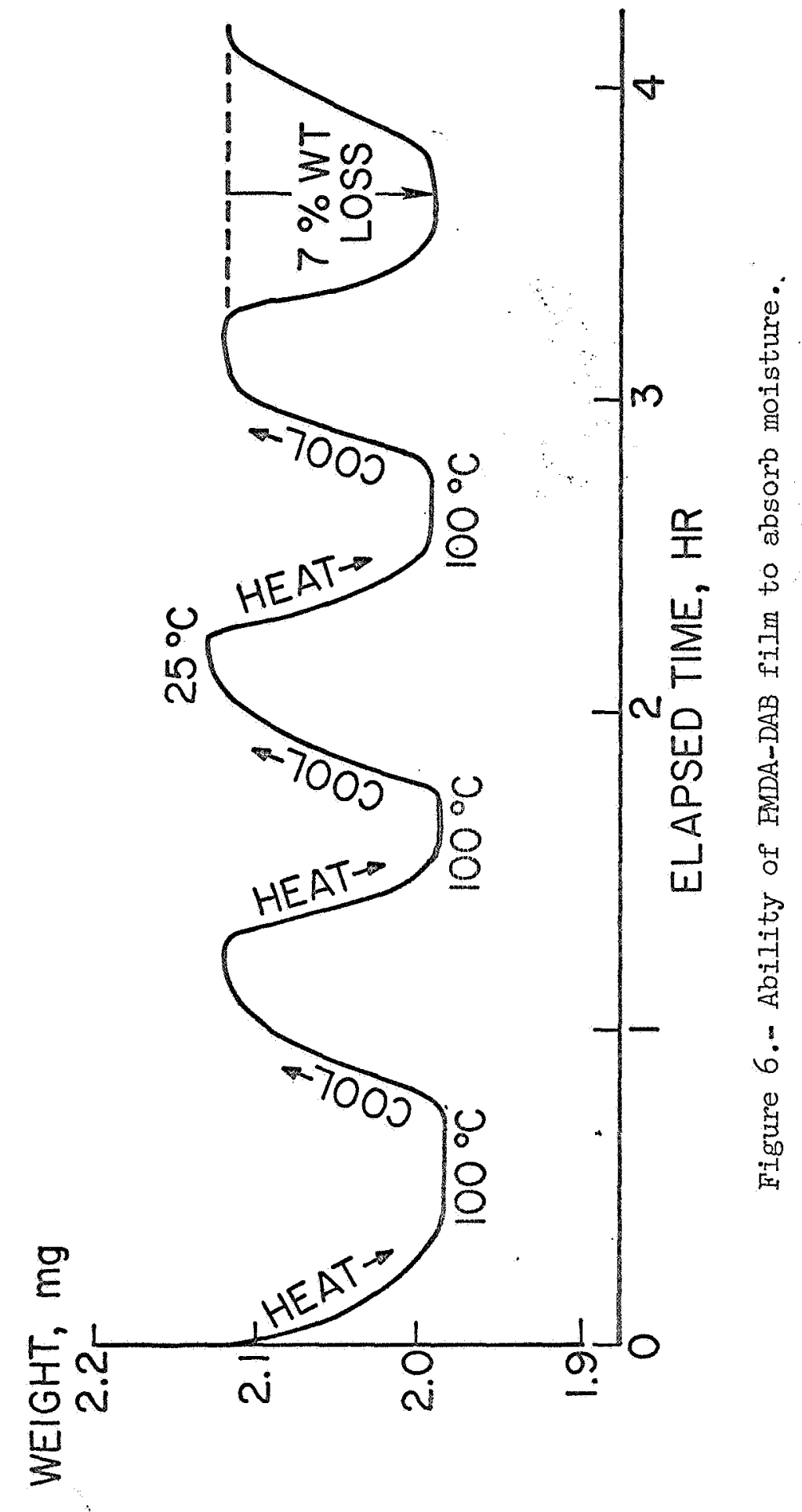


SAMPLE: BTDA-DAB

SIZE: $2 \mathrm{mg}$

$589^{\circ}\left(7.5^{\circ} \mathrm{C} / \mathrm{MIN}\right)$

ATM. AIR

PRECONDITIONING:

$100^{\circ} \mathrm{C}$ FOR $30 \mathrm{MIN}$

$581^{\circ}\left(6.0^{\circ} \mathrm{C} / \mathrm{MIN}\right)$

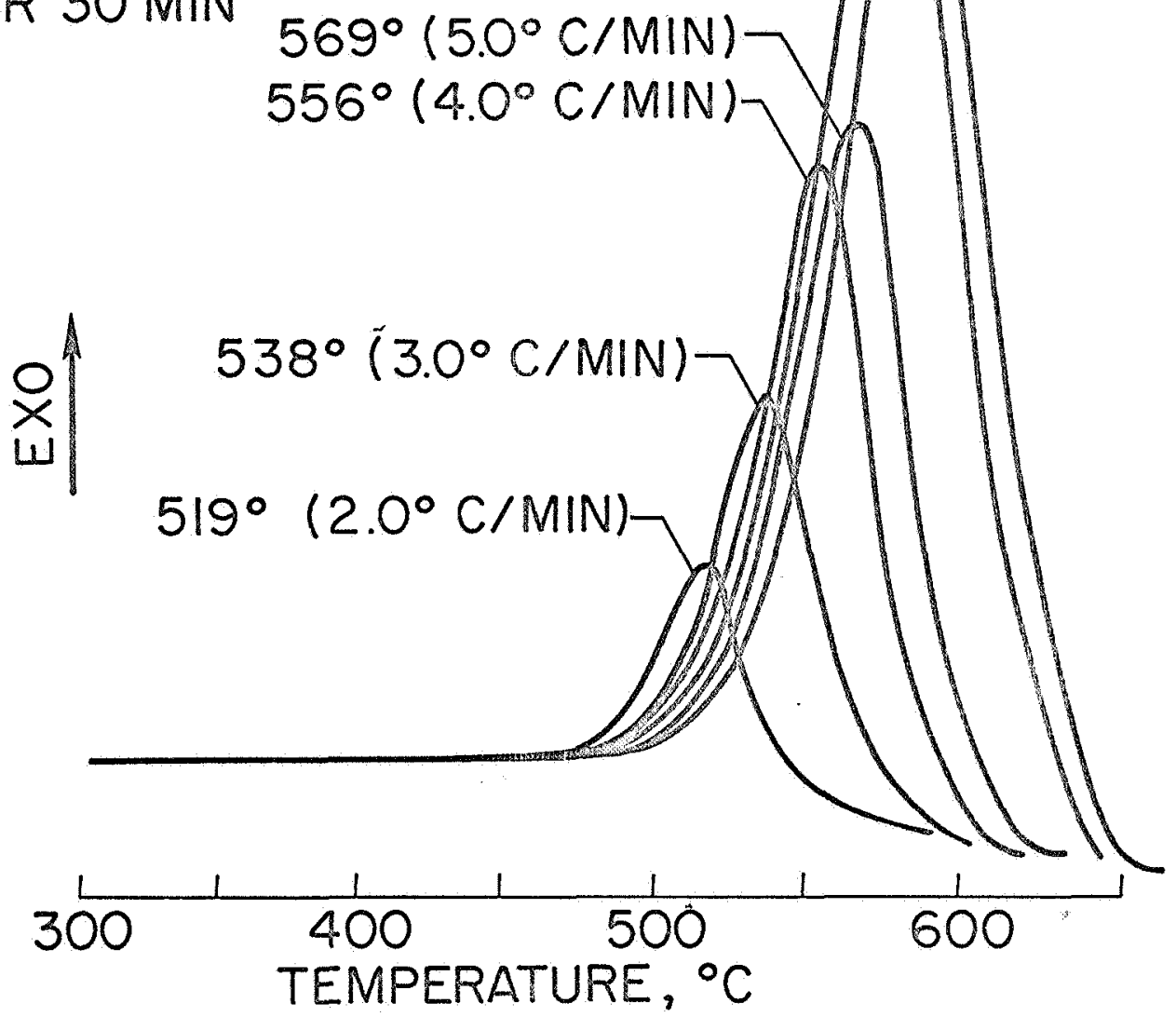

Figure 7.- DNA thermograms in air for BIDA-DAB film. 


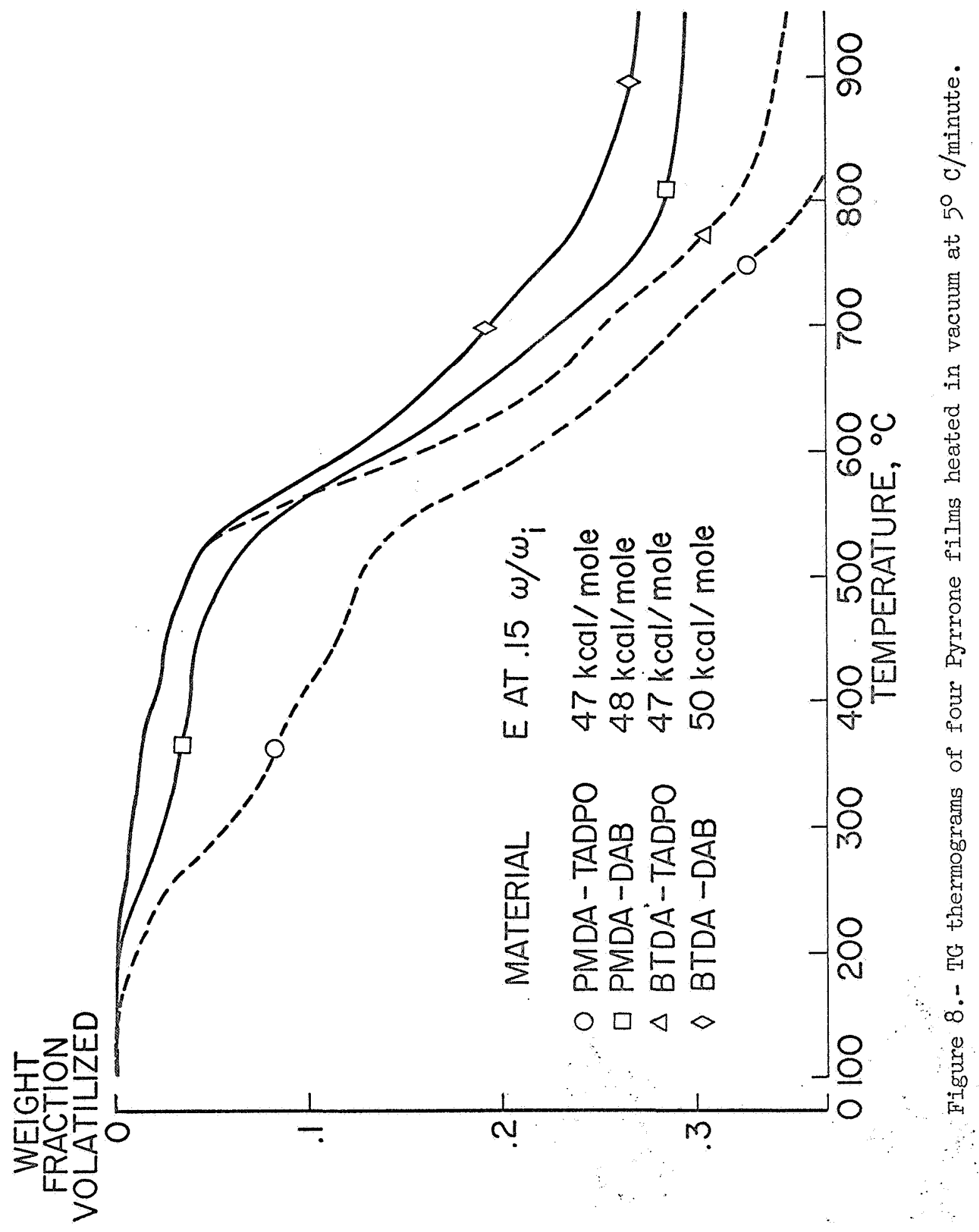




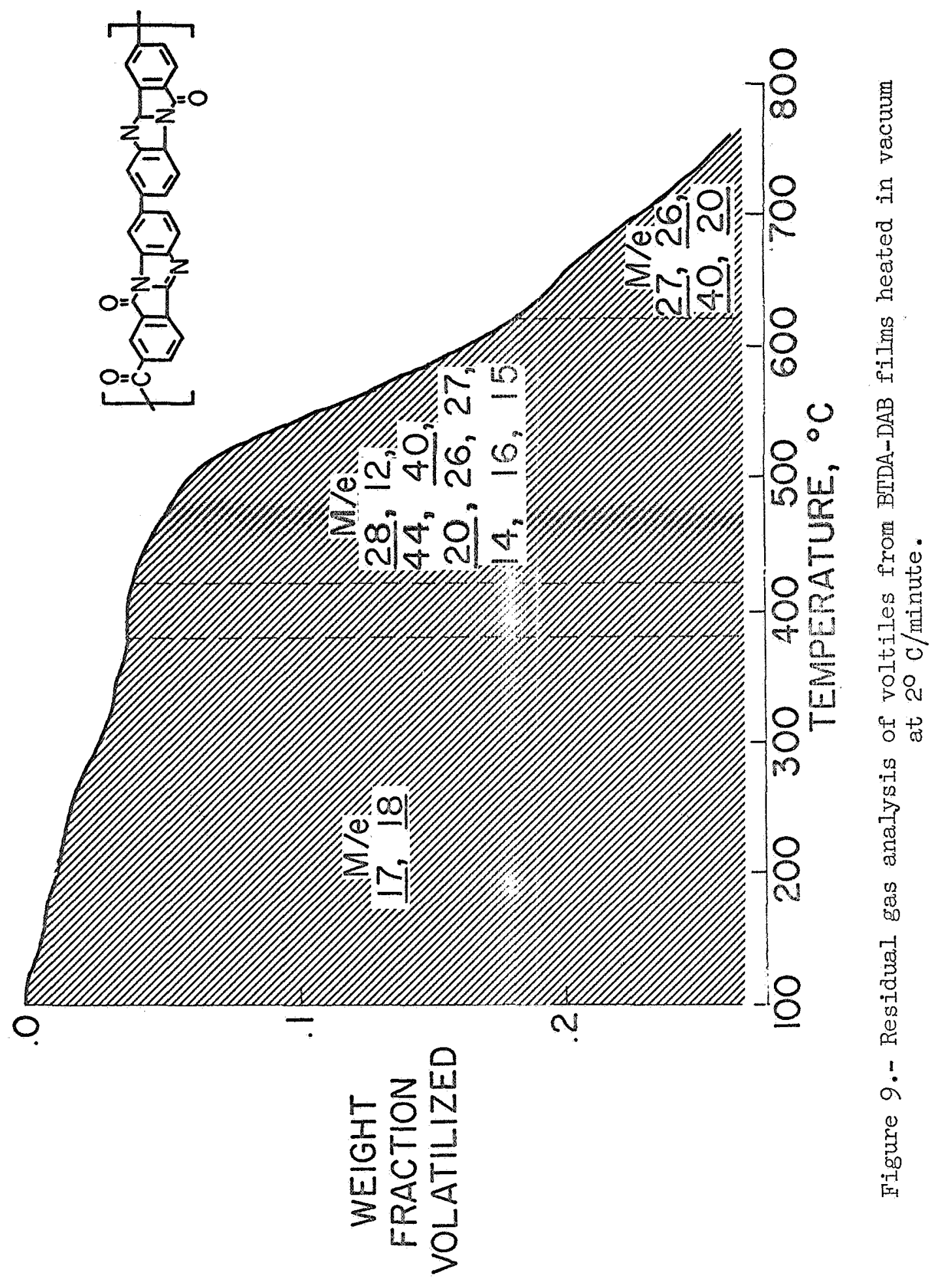

